\title{
Cumulene carbenes in TMC-1: Astronomical discovery of $I-\mathrm{H}_{2} \mathrm{C}_{5}$ 太
}

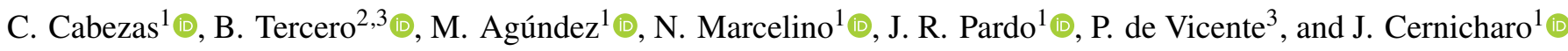 \\ 1 Grupo de Astrofísica Molecular, Instituto de Física Fundamental (IFF-CSIC), C/ Serrano 121, 28006 Madrid, Spain \\ e-mail: carlos.cabezas@csic.es, jose.cernicharo@csic.es \\ 2 Observatorio Astronómico Nacional (IGN), C/ Alfonso XII, 3, 28014 Madrid, Spain \\ 3 Centro de Desarrollos Tecnológicos, Observatorio de Yebes (IGN), 19141 Yebes, Guadalajara, Spain
}

Received 8 May 2021 / Accepted 31 May 2021

\begin{abstract}
We report the first detection in space of the cumulene carbon chain $l-\mathrm{H}_{2} \mathrm{C}_{5}$. A total of eleven rotational transitions, with $J_{\text {up }}=7-10$ and $K_{a}=0$ and 1 , were detected in TMC-1 in the 31.0-50.4 GHz range using the Yebes $40 \mathrm{~m}$ radio telescope. We derived a column density of $(1.8 \pm 0.5) \times 10^{10} \mathrm{~cm}^{-2}$. In addition, we report observations of other cumulene carbenes detected previously in TMC-1 in order to compare their abundances with the newly detected cumulene carbene chain. We find that $l-\mathrm{H}_{2} \mathrm{C}_{5}$ is $\sim 4.0$ times less abundant than the larger cumulene carbene $l-\mathrm{H}_{2} \mathrm{C}_{6}$, while it is $\sim 300$ and $\sim 500$ times less abundant than the shorter chains $l-\mathrm{H}_{2} \mathrm{C}_{3}$ and $l-\mathrm{H}_{2} \mathrm{C}_{4}$. We discuss the most likely gas-phase chemical routes to these cumulenes in TMC- 1 and stress that chemical kinetics studies able to distinguish between different isomers are needed to shed light on the chemistry of $\mathrm{C}_{n} \mathrm{H}_{2}$ isomers with $n>3$.
\end{abstract}

Key words. astrochemistry - ISM: molecules - ISM: individual objects: TMC-1 - line: identification - molecular data

\section{Introduction}

Cumulene carbenes are highly polar carbon chains with the elemental formula $\mathrm{H}_{2} \mathrm{C}_{n}$. They contain consecutive carbon-carbon double bonds and two non-bonded electrons localised on the terminal $\mathrm{C}$ atom. These species play major roles as reaction intermediates in combustion and plasma processes and they are also of astrophysical interest since some of them have been detected in interstellar and circumstellar environments. The first astronomical discovery of the simplest cumulene carbene propadienylidene, $l-\mathrm{H}_{2} \mathrm{C}_{3}$, was carried out by Cernicharo et al. (1991a) towards the cold dark cloud TMC-1. Butatrienylidene, $l-\mathrm{H}_{2} \mathrm{C}_{4}$, was detected in the carbon-rich circumstellar envelope of IRC +10216 by Cernicharo et al. (1991b) and in TMC-1 by Kawaguchi et al. (1991). Also, later, the larger cumulene carbene hexapentaenylidene, $l-\mathrm{H}_{2} \mathrm{C}_{6}$, was detected in TMC-1, IRC+10216, and $\mathrm{L} 1527$ (Langer et al. 1997; Guélin et al. 2000; Araki et al. 2017).

Cumulene carbenes are metastable isomers, lying 0.5 and $0.6 \mathrm{eV}$ above the most stable isomer, which is a polyacetylene $\left(\mathrm{HC}_{n} \mathrm{H}\right)$ for an even $n$ or a cyclic structure when the number of carbon atoms is odd. Thus, their astronomical detection demonstrates how far from thermochemical equilibrium the composition of interstellar clouds is. The case of $\mathrm{HNC}$, which is less stable than $\mathrm{HCN}$ by about $0.6 \mathrm{eV}$ but as abundant as $\mathrm{HCN}$ (Herbst 1978), illustrates this point as well.

Pentatetraenylidene, $l-\mathrm{H}_{2} \mathrm{C}_{5}$, is the cumulene carbene from the isomeric family with formula $\mathrm{C}_{5} \mathrm{H}_{2}$. We note that $l-\mathrm{H}_{2} \mathrm{C}_{5}$ is a high energy isomer and lies $0.564 \mathrm{eV}$ above the most stable isomers, the non-polar pentadiynylidene $(\mathrm{HCCCCH})$ and ethynyl cyclopropenylidene $\left(c-\mathrm{C}_{3} \mathrm{HCCH}\right)$, whose energy separation is very small $\sim 0.043 \mathrm{eV}$. Two other species are part of this isomeric

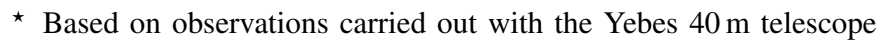
(projects 19A003, 20A014, and 20D15). The $40 \mathrm{~m}$ radiotelescope at Yebes Observatory is operated by the Spanish Geographic Institute (IGN, Ministerio de Transportes, Movilidad y Agenda Urbana). family, $\mathrm{HCCCHCC}$ and $c-\mathrm{C}_{3} \mathrm{H}_{2} \mathrm{C}_{2}$, placed at 0.737 and $0.910 \mathrm{eV}$ above the most stable forms, respectively (Seburg et al. 1997). All these isomers, except the non-polar $\mathrm{HCCCCH}$, have been studied in the laboratory (Travers et al. 1997; McCarthy et al. 1997; Gottlieb et al. 1998) and, thus, their transition frequencies are well known. However, until very recently, none of them had been observed in space. Cernicharo et al. (2021a) have reported the first identification in TMC-1 of the most stable isomer of this family, $c-\mathrm{C}_{3} \mathrm{HCCH}$, using a high sensitivity line survey gathered with the Yebes $40 \mathrm{~m}$ radio telescope. This achievement opens the door to the identification of high energy isomers of this family in TMC-1.

In this Letter, we report the first identification of the $l-\mathrm{H}_{2} \mathrm{C}_{5}$ cumulene carbene in space towards TMC-1 and a comparative study of the previously detected cumulene carbenes in this source. The derived column densities for these singular energetic species are interpreted by chemical models and used to understand the chemical processes leading to their formation.

\section{Observations}

The data presented in this work are part of a deep spectral line survey in the $Q$ band towards TMC-1 $\left(\alpha_{J 2000}=4^{\mathrm{h}} 41^{\mathrm{m}} 41.9^{\mathrm{s}}\right.$ and $\left.\delta_{J 2000}=+25^{\circ} 41^{\prime} 27.0^{\prime \prime}\right)$ that was performed at the Yebes $40 \mathrm{~m}$ radio telescope between November 2019 and April 2021. The survey was done using new receivers, built within the Nanocosmos project ${ }^{1}$ consisting of two HEMT cold amplifiers covering the 31.0-50.4 GHz band with horizontal and vertical polarisations. Fast Fourier transform spectrometers (FFTSs) with $8 \times 2.5 \mathrm{GHz}$ bands per lineal polarisation allow a simultaneous scan of a bandwidth of $18 \mathrm{GHz}$ at a spectral resolution of $38.15 \mathrm{kHz}$. This setup has been described before by Tercero et al. (2021).

The observations were performed using the frequency switching technique with a frequency throw of $10 \mathrm{MHz}$ or

1 https://nanocosmos.iff.csic.es/ 
$8 \mathrm{MHz}$ (see, e.g., Cernicharo et al. 2021b,c). The intensity scale, that is the antenna temperature $\left(T_{\mathrm{A}}^{*}\right)$, for the two telescopes used in this work was calibrated using two absorbers at different temperatures and the atmospheric transmission model (ATM; Cernicharo 1985; Pardo et al. 2001). Different frequency coverages were observed, $31.08-49.52 \mathrm{GHz}$ and $31.98-50.42 \mathrm{GHz}$, which permitted us to check that no spurious ghosts are produced in the down-conversion chain. The signal coming from the receiver was downconverted to $1-19.5 \mathrm{GHz}$ and then split into eight bands with a coverage of $2.5 \mathrm{GHz}$, each of which were analysed by the FFTs.

Pointing and focus corrections were obtained by observing strong $\mathrm{SiO}$ masers towards nearby evolved stars (IKTau and UOri). Pointing errors were always within $2^{\prime \prime}-3^{\prime \prime}$. Total calibration uncertainties have been adopted to be $10 \%$ based on the observed repeatability of the line intensities between different observing runs. All data have been analysed using the GILDAS package ${ }^{2}$.

\section{Results and discussion}

\subsection{Detection of $l-H_{2} C_{5}$ in $T M C-1$}

McCarthy et al. (1997) observed $l-\mathrm{H}_{2} \mathrm{C}_{5}$ in the laboratory and the prediction of its rotational spectrum is available in the CDMS (Müller et al. 2005). This prediction, based on the laboratory data from McCarthy et al. (1997), is implemented in the MADEX code (Cernicharo 2012) that was used to identify the spectral features in our TMC-1 $Q$-band survey. McCarthy et al. (1997) observed in the laboratory a total of nine rotational transitions for $l-\mathrm{H}_{2} \mathrm{C}_{5}$ up to $J_{\text {up }}=5$ at $23 \mathrm{GHz}$. The derived parameters from McCarthy et al. (1997) (see Table 1) allowed us to accurately predict the rotational transitions for $l-\mathrm{H}_{2} \mathrm{C}_{5}$ in the $Q$-band. The molecule has a dipole moment of 5.9 D (Maluendes \& McLean 1992), which makes it a very promising candidate to be observed in our TMC-1 data. In this manner, we searched for this species in our TMC-1 survey and we found a total of eleven transitions ranging from $J_{\text {up }}=7-10$, whose frequencies agree very well with those predicted; discrepancies are smaller than $25 \mathrm{kHz}$. The $9_{0,9}-8_{0,8}$ line is blended with a negative feature produced in the folding of the frequency switching data, while the $10_{0,10}-9_{0,9}$ transition is not detected due to the limited sensitivity at the predicted frequency. In any case, the non-detection is consistent with the expected intensity. All the $l-\mathrm{H}_{2} \mathrm{C}_{5}$ lines observed in TMC- 1 , shown in Fig. 1 and listed in Table 2, were analysed, together with those observed in laboratory, using an asymmetric rotor Hamiltonian with the FITWAT code (Cernicharo et al. 2018) to derive the rotational and centrifugal distortion constants. The results from this fit are shown in Table 1 together with those obtained by McCarthy et al. (1997) only with laboratory data. With this new global fit, an improvement of the uncertainty in the rotational and distortion constants is obtained. Hence, this fit is recommended to predict the frequency of the rotational transitions of $l-\mathrm{H}_{2} \mathrm{C}_{5}$ with uncertainties between 10 and $200 \mathrm{kHz}$ in the $50-116 \mathrm{GHz}$ frequency range.

As $l-\mathrm{H}_{2} \mathrm{C}_{5}$ has $\mathrm{C}_{2 \mathrm{v}}$ symmetry, it is necessary to discern between ortho- $l-\mathrm{H}_{2} \mathrm{C}_{5}$ and para- $l-\mathrm{H}_{2} \mathrm{C}_{5}$. The ortho levels are described by $K_{a}$ odd, while the para levels are described by $K_{a}$ even. The nuclear spin weights are three and one for ortho- $l$ $\mathrm{H}_{2} \mathrm{C}_{5}$ and para- $l-\mathrm{H}_{2} \mathrm{C}_{5}$, respectively. The $J_{K_{a}, K_{c}}=1_{1,1}$ is the lowest ortho energy state located $13.4 \mathrm{~K}$ above the para ground level, $J_{K_{a}, K_{c}}=0_{0,0}$. Hence, from the eleven observed lines, eight of them correspond to ortho- $l-\mathrm{H}_{2} \mathrm{C}_{5}$ and the remaining three correspond to para- $l-\mathrm{H}_{2} \mathrm{C}_{5}$. An analysis of the line intensities through

\footnotetext{
2 http://www.iram.fr/IRAMFR/GILDAS
}

Table 1. New derived rotational parameters (in megahertz) for $l-\mathrm{H}_{2} \mathrm{C}_{5}$.

\begin{tabular}{lcc}
\hline \hline Constant & TMC-1+Lab $^{(a)}$ & Lab $^{(b)}$ \\
\hline$A$ & $277600.0^{(c)}$ & 277600.0 \\
$B$ & $2304.78432(27)$ & $2304.7844(3)$ \\
$C$ & $2285.80518(27)$ & $2285.8053(3)$ \\
$\Delta_{J} \times 10^{3}$ & $0.0978(19)$ & $0.104(6)$ \\
$\Delta_{J K}$ & $0.04647(19)$ & $0.0464(2)$ \\
$\mathrm{rms}$ & 8.7 & 3.0 \\
$J_{\min } / J_{\max }$ & $2 / 10$ & $2 / 5$ \\
$K_{\min } / K_{\max }$ & $0 / 1$ & $0 / 1$ \\
$N^{(e)}$ & 20 & 9 \\
\hline
\end{tabular}

Notes. ${ }^{(a)}$ Fit to the lines of $l-\mathrm{H}_{2} \mathrm{C}_{5}$ observed in TMC-1 and in laboratory (McCarthy et al. 1997). ${ }^{(b)}$ (McCarthy et al. 1997). ${ }^{\left({ }^{c}\right)}$ Fixed to the value reported by McCarthy et al. (1997). ${ }^{(d)}$ The standard deviation of the fit in kilohertz. ${ }^{(e)}$ Number of lines included in the fit.

a line model fitting procedure by Cernicharo et al. (2021a) provides a rotational temperature of $\sim 10 \mathrm{~K}$ and column densities of $\mathrm{N}\left(\right.$ ortho- $\left.l-\mathrm{H}_{2} \mathrm{C}_{5}\right)=(1.3 \pm 0.3) \times 10^{10} \mathrm{~cm}^{-1}$ and $\mathrm{N}($ para- $l$ $\left.\mathrm{H}_{2} \mathrm{C}_{5}\right)=(5.0 \pm 2.0) \times 10^{9} \mathrm{~cm}^{-1}$. The ortho/para ratio was calculated to be $2.6 \pm 1.5$. We have assumed a linewidth of $0.6 \mathrm{~km} \mathrm{~s}^{-1}$ and a source of uniform brightness temperature with a diameter of $80^{\prime \prime}$ (Fossé et al. 2001). Figure 1 shows the computed synthetic spectrum in red.

\subsection{Column densities for $l-\mathrm{H}_{2} \mathrm{C}_{3}, l-\mathrm{H}_{2} \mathrm{C}_{4}$, and $l-\mathrm{H}_{2} \mathrm{C}_{6}$ in TMC-1}

The carbene $l-\mathrm{H}_{2} \mathrm{C}_{3}$ is the smallest cumulene species studied in this work. The laboratory spectroscopic data used to predict the $l-\mathrm{H}_{2} \mathrm{C}_{3}$ spectrum were reported by Vrtilek et al. (1990). The electric dipole moment calculated for this molecule is 4.1 D (Defrees \& McLean 1986). As for $l-\mathrm{H}_{2} \mathrm{C}_{5}, l-\mathrm{H}_{2} \mathrm{C}_{3}$ has $\mathrm{C}_{2 \mathrm{v}}$ symmetry and, thus, it is necessary to discern between ortho and para $l-\mathrm{H}_{2} \mathrm{C}_{3}$. In the same manner than for $l-\mathrm{H}_{2} \mathrm{C}_{5}$, the ortho levels are described by $K_{a}$ odd while the para levels are described by $K_{a}$ even, with a 3/1 ratio for ortho/para. Only three rotational transitions for $l-\mathrm{H}_{2} \mathrm{C}_{3}$ lie within the $31.0-50.4 \mathrm{GHz}$ frequency range. One transition, $2_{0,2}-1_{0,1}$, corresponds to para$l-\mathrm{H}_{2} \mathrm{C}_{3}$ and the other two, $2_{1,2}-1_{1,1}$ and $2_{1,1}-1_{1,0}$, are ortho- $l$ $\mathrm{H}_{2} \mathrm{C}_{3}$ transitions. The lines are shown in Fig. 2, while the line parameters are collected in Table 2. The position of the lines is consistent with the calculated frequencies and the systemic velocity of the source, $V_{\mathrm{LSR}}=5.83 \mathrm{~km} \mathrm{~s}^{-1}$ (Cernicharo et al. 2020). We assumed $T_{r}=10 \mathrm{~K}$ and the column densities N(ortho- $l$ $\left.\mathrm{H}_{2} \mathrm{C}_{3}\right)=(1.5 \pm 0.5) \times 10^{12} \mathrm{~cm}^{-1}$ and $\mathrm{N}\left(\right.$ para- $\left.l-\mathrm{H}_{2} \mathrm{C}_{3}\right)=(4.0 \pm 1.2) \times$ $10^{11} \mathrm{~cm}^{-1}$. The ortho/para ratio was calculated to be $3.8 \pm 1.1$. Collisional rates are available for the system $l-\mathrm{H}_{2} \mathrm{C}_{3} / \mathrm{He}$ (Khalifa et al. 2019). Adopting a volume density for TMC-1 of $4 \times 10^{4} \mathrm{~cm}^{-} 3$ (Cernicharo \& Guélin 1987; Fossé et al. 2001), we derived an excitation temperature for the two ortho transitions of $\sim 9 \mathrm{~K}$, and of $\sim 8.5 \mathrm{~K}$ for the para transition. Hence, the adopted rotational temperature seems well adapted to the excitation conditions of this molecule.

The next member of the $l-\mathrm{H}_{2} \mathrm{C}_{n}$ family is $l-\mathrm{H}_{2} \mathrm{C}_{4}$. The rotational spectrum for this cumulene was observed by Killian et al. (1990) and Travers et al. (1996). From ab initio calculations for the dipole moment of $l-\mathrm{H}_{2} \mathrm{C}_{4}$ was estimated to be $4.1 \mathrm{D}$ (Oswald \& Botschwina 1995), similar to the smaller cumulene carbene $l-\mathrm{H}_{2} \mathrm{C}_{3}$. The lines for ortho- and para- $l-\mathrm{H}_{2} \mathrm{C}_{4}$ are clearly detected in our TMC-1 survey, as can be seen in Fig. 3. However, it should be noted that there are small discrepancies (of 


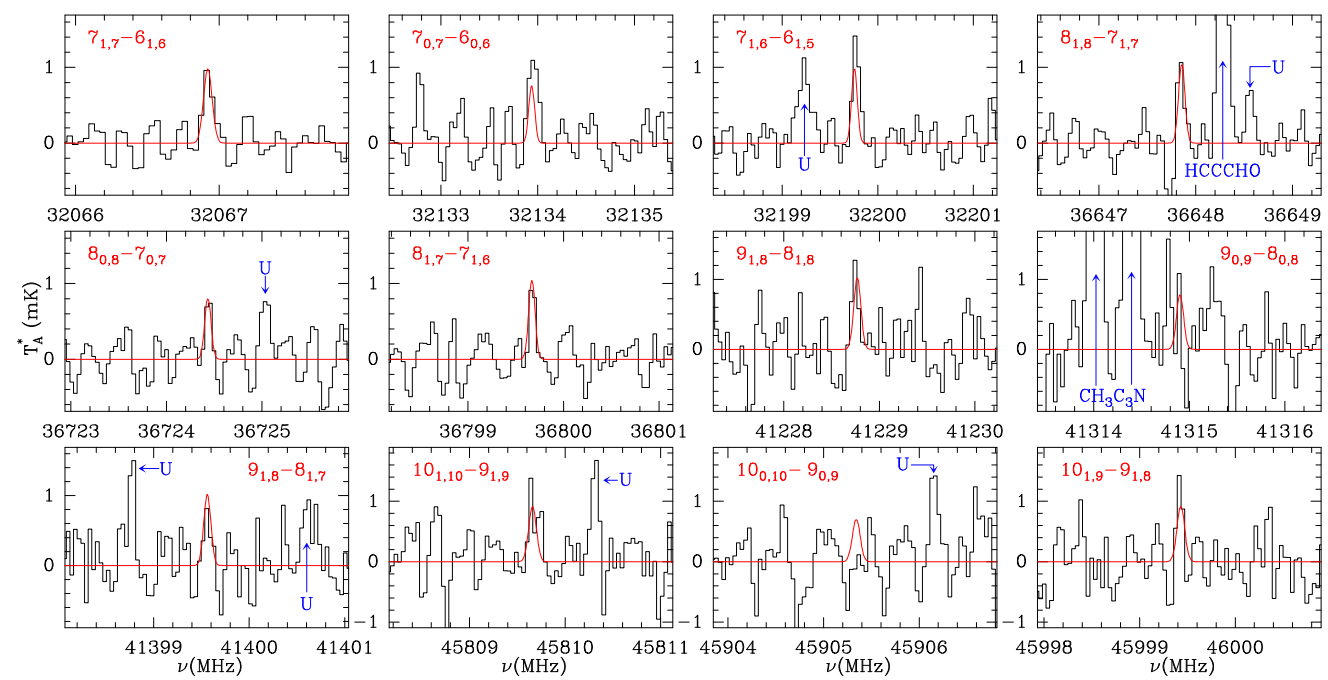

Fig. 1. Observed lines of $l-\mathrm{H}_{2} \mathrm{C}_{5}$ in TMC-1 in the $31.0-50.4 \mathrm{GHz}$ range. The abscissa corresponds to the rest frequency assuming a local standard of rest velocity of $5.83 \mathrm{~km} \mathrm{~s}^{-1}$. The ordinate is antenna temperature in millikelvins. Curves shown in red are the computed synthetic spectra. The label $\mathrm{U}$ corresponds to features above $4 \sigma$. Frequencies and line parameters are given in Table 2.

Table 2. Line parameters for the lines of $l-\mathrm{H}_{2} \mathrm{C}_{3}, l-\mathrm{H}_{2} \mathrm{C}_{4}, l-\mathrm{H}_{2} \mathrm{C}_{5}$, and $l-\mathrm{H}_{2} \mathrm{C}_{6}$ observed in TMC-1.

\begin{tabular}{|c|c|c|c|c|c|c|c|c|}
\hline State & $\begin{array}{c}\text { Transition } \\
\left(J_{K_{a}, K_{c}}\right)_{u}-\left(J_{K_{a}, K_{c}}\right)_{l}\end{array}$ & $\begin{array}{l}\text { Rest freq. } \\
(\mathrm{MHz})\end{array}$ & $\begin{array}{c}E_{\text {up }} \\
(\mathrm{K})\end{array}$ & $S_{i j}$ & $\begin{array}{l}\int T_{\mathrm{A}}^{*} \mathrm{~d} v \\
\left(\mathrm{mK} \mathrm{km} \mathrm{s}^{-1}\right)\end{array}$ & $\begin{array}{l}V_{\mathrm{LSR}} \\
\left(\mathrm{km} \mathrm{s}^{-1}\right)\end{array}$ & $\begin{array}{l}\Delta v \\
\left(\mathrm{~km} \mathrm{~s}^{-1}\right)\end{array}$ & $\begin{array}{r}T_{\mathrm{A}}^{*} \\
(\mathrm{mK})\end{array}$ \\
\hline \multicolumn{9}{|c|}{$l-\mathrm{H}_{2} \mathrm{C}_{3}$} \\
\hline ortho & $2_{1,2}-1_{1,1}$ & $41198.335(2)$ & 2.0 & 1.50 & $72.0208(2)$ & 5.71(1) & $0.61(1)$ & $110.3(3)$ \\
\hline para & $20,2-1_{0,1}$ & $41584.675(1)$ & 3.0 & 2.00 & $50.0199(4)$ & $5.75(1)$ & $0.58(1)$ & $81.11(3)$ \\
\hline ortho & $2,1-1_{1,0}$ & $41967.671(2)$ & 2.0 & 1.50 & $72.2521(2)$ & $5.75(1)$ & $0.56(1)$ & $122.5(3)$ \\
\hline \multicolumn{9}{|c|}{$l-\mathrm{H}_{2} \mathrm{C}_{4}$} \\
\hline ortho & $4_{1,4}-3_{1,3}$ & $35577.008(2)$ & 3.8 & 3.75 & $137.590(1)$ & $5.71(1)$ & $0.70(1)$ & $185.3(2)$ \\
\hline para & $4_{0,4}-3_{0,3}$ & $35727.379(1)$ & 4.3 & 4.00 & $91.6939(2)$ & $5.53(1)$ & $0.67(1)$ & $128.0(2)$ \\
\hline ortho & $4_{1,3}-3_{1,2}$ & $35875.775(2)$ & 3.9 & 3.75 & $140.130(1)$ & $5.69(1)$ & $0.69(1)$ & $189.9(2)$ \\
\hline ortho & $5_{1,5}-4_{1,4}$ & $44471.137(2)$ & 6.0 & 4.80 & $120.160(1)$ & $5.72(1)$ & $0.57(1)$ & $199.4(4)$ \\
\hline para & $5_{0,5}-4_{0,4}$ & $44659.015(1)$ & 6.0 & 5.00 & $73.0765(2)$ & $5.58(1)$ & $0.58(1)$ & $119.2(4)$ \\
\hline ortho & $5_{1,4}-4_{1,3}$ & $44844.590(2)$ & 6.4 & 4.80 & $117.010(1)$ & $5.70(1)$ & $0.59(1)$ & $186.6(4)$ \\
\hline \multicolumn{9}{|c|}{$l-\mathrm{H}_{2} \mathrm{C}_{5}{ }^{(a)}$} \\
\hline ortho & $7_{1,7}-6_{1,6}$ & $32066.923(10)$ & 5.9 & 6.86 & $0.6759(5)$ & $5.83^{(b)}$ & $0.69(17)$ & $0.9(2)$ \\
\hline para & $7_{0,7}-6_{0,6}$ & $32133.955(10)$ & 6.2 & 7.00 & $1.3465(2)$ & 5.83 & $1.06(16)$ & $1.2(2)$ \\
\hline ortho & $7_{1,6}-6_{1,5}$ & $32199.773(10)$ & 6.0 & 6.86 & $1.1423(2)$ & 5.83 & $0.77(12)$ & $1.4(2)$ \\
\hline ortho & $8_{1,8}-7_{1,7}$ & $36647.828(10)$ & 7.7 & 7.88 & $0.7123(5)$ & 5.83 & $0.58(13)$ & $1.2(3)$ \\
\hline para & $8_{0,8}-7_{0,7}$ & $36724.441(10)$ & 7.9 & 8.00 & $0.5152(11)$ & 5.83 & $0.53(23)$ & $0.9(3)$ \\
\hline ortho & $8_{1,7}-7_{1,6}$ & $36799.676(10)$ & 7.7 & 7.88 & $0.5908(7)$ & 5.83 & $0.48(19)$ & $1.2(2)$ \\
\hline ortho & $9_{1,9}-8_{1,8}$ & $41228.743(10)$ & 9.7 & 8.89 & $0.7447(6)$ & 5.83 & $0.54(16)$ & $1.2(4)$ \\
\hline para & $9_{0,9}-8_{0,8}$ & $41314.893(30)$ & 9.9 & 9.00 & $\ldots{ }^{(c)}$ & 5.83 & $\ldots$ & $\ldots$ \\
\hline ortho & $9_{1,8}-8_{1,7}$ & $41399.559(10)$ & 9.7 & 8.89 & $0.4890(14)$ & 5.83 & $0.59(29)$ & $0.8(4)$ \\
\hline ortho & $10_{1,10}-9_{1,9}$ & $45809.644(10)$ & 11.9 & 9.90 & $0.5462(8)$ & 5.83 & $0.37(11)$ & $1.4(4)$ \\
\hline ortho & $10_{1,9}-9_{1,8}$ & $45999.420(10)$ & 11.9 & 9.90 & $0.6841(5)$ & 5.83 & $0.42(10)$ & $1.5(4)$ \\
\hline \multicolumn{9}{|c|}{$l-\mathrm{H}_{2} \mathrm{C}_{6}$} \\
\hline ortho & $12_{1,12}-11_{1,11}$ & $32232.270(6)$ & 9.9 & 11.9 & $3.89347(2)$ & $5.82(2)$ & $0.80(5)$ & $4.6(2)$ \\
\hline para & $12_{0,12}-11_{0,11}$ & $32273.061(6)$ & 10.1 & 12.0 & $2.25233(5)$ & $5.86(3)$ & $0.73(7)$ & $2.9(2)$ \\
\hline ortho & $12_{1,11}-11_{1,10}$ & $32313.117(6)$ & 10.0 & 11.9 & $4.17934(2)$ & $5.83(2)$ & $0.81(5)$ & $4.8(3)$ \\
\hline ortho & $13_{1,13}-12_{1,12}$ & $34918.254(8)$ & 11.6 & 12.9 & $3.58530(2)$ & $5.84(2)$ & $0.66(4)$ & $5.1(3)$ \\
\hline para & $13_{0,13}-12_{0,12}$ & $34962.439(8)$ & 11.7 & 13.0 & $2.61780(6)$ & $5.86(4)$ & $0.91(9)$ & $2.7(3)$ \\
\hline ortho & $13_{1,12}-12_{1,11}$ & $35005.838(8)$ & 11.6 & 12.9 & $3.52717(2)$ & $5.83(1)$ & $0.70(4)$ & $4.7(2)$ \\
\hline ortho & $14_{1,14}-13_{1,13}$ & $37604.22(1)$ & 13.4 & 13.9 & $2.95633(3)$ & $5.80(2)$ & $0.67(4)$ & 4.1(2) \\
\hline para & $14_{0,14}-13_{0,13}$ & $37651.80(1)$ & 13.6 & 14.0 & $1.73602(10)$ & $5.83(4)$ & $0.70(9)$ & $2.3(3)$ \\
\hline ortho & $14_{1,13}-13_{1,12}$ & $37698.54(1)$ & 13.4 & 13.9 & $2.87938(3)$ & $5.80(2)$ & $0.73(5)$ & $3.7(2)$ \\
\hline ortho & $15_{1,15}-14_{1,14}$ & $40290.19(1)$ & 15.3 & 14.9 & $2.58873(5)$ & $5.75(2)$ & $0.56(5)$ & 4.4(4) \\
\hline para & $15_{0,15}-14_{0,14}$ & $40341.16(1)$ & 15.5 & 15.0 & $1.95729(10)$ & $5.87(5)$ & $0.76(9)$ & $2.4(4)$ \\
\hline ortho & $15_{1,14}-14_{1,13}$ & $40391.25(1)$ & 15.4 & 14.9 & $2.47566(5)$ & $5.91(3)$ & $0.65(8)$ & $3.6(2)$ \\
\hline ortho & $16_{1,16}-15_{1,15}$ & $42976.15(2)$ & 17.4 & 15.9 & $1.2139(2)$ & $5.92(4)$ & $0.48(7)$ & $2.4(3)$ \\
\hline para & $16_{0,16}-15_{0,15}$ & $43030.51(2)$ & 17.6 & 16.0 & $0.7463(4)$ & $5.80(6)$ & $0.50(12)$ & 1.4(3) \\
\hline ortho & $16_{1,15}-15_{1,14}$ & 43083.94(2) & 17.4 & 15.9 & $1.61939(11)$ & $5.88(3)$ & $0.62(8)$ & $2.5(3)$ \\
\hline ortho & $17_{1,17}-16_{1,16}$ & $45662.09(2)$ & 19.6 & 16.9 & $1.0792(4)$ & $5.86(9)$ & $0.68(23)$ & $1.5(5)$ \\
\hline para & $17_{0,17}-16_{0,16}$ & $45719.84(2)$ & 19.7 & 17.0 & $1.3389(2)$ & $5.92(6)$ & $0.61(12)$ & $2.1(4)$ \\
\hline ortho & $17_{1,16}-16_{1,15}$ & $45776.62(2)$ & 19.6 & 16.9 & $0.6063(12)$ & $5.85(9)$ & $0.45(24)$ & $1.3(6)$ \\
\hline ortho & $18_{1,18}-17_{1,17}$ & $48348.02(2)$ & 21.9 & 17.9 & $1.3459(3)$ & $5.72(9)$ & $0.68(19)$ & $1.8(6)$ \\
\hline para & $18_{0,18}-17_{0,17}$ & $48409.16(2)$ & 22.1 & 18.0 & $0.36152(11)$ & $5.82(9)$ & $0.23(90)$ & $1.4(6)$ \\
\hline ortho & $18_{1,17}-17_{1,16}$ & $48469.29(2)$ & 22.0 & 17.9 & $0.37677(10)$ & $6.27(5)$ & $0.23(90)$ & $1.5(6)$ \\
\hline
\end{tabular}

Notes. Numbers in parentheses indicate the uncertainty in units of the last significant digits. For the observational parameters we adopted the uncertainty of the Gaussian fit provided by GILDAS. ${ }^{(a)}$ For $l-\mathrm{H}_{2} \mathrm{C}_{5}$ the frequencies are those measured in our survey. ${ }^{(b)}$ Assumed $V_{\mathrm{LSR}} \cdot{ }^{(c)}$ Onechannel spectral feature. 


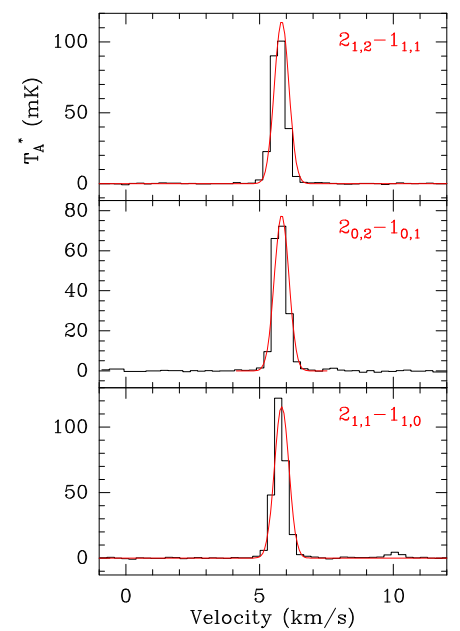

Fig. 2. Observed lines of $l-\mathrm{H}_{2} \mathrm{C}_{3}$ in TMC-1 in the 31.0-50.4 GHz range. Curves shown in red are the computed synthetic spectra. Frequencies and line parameters are given in Table 2 .
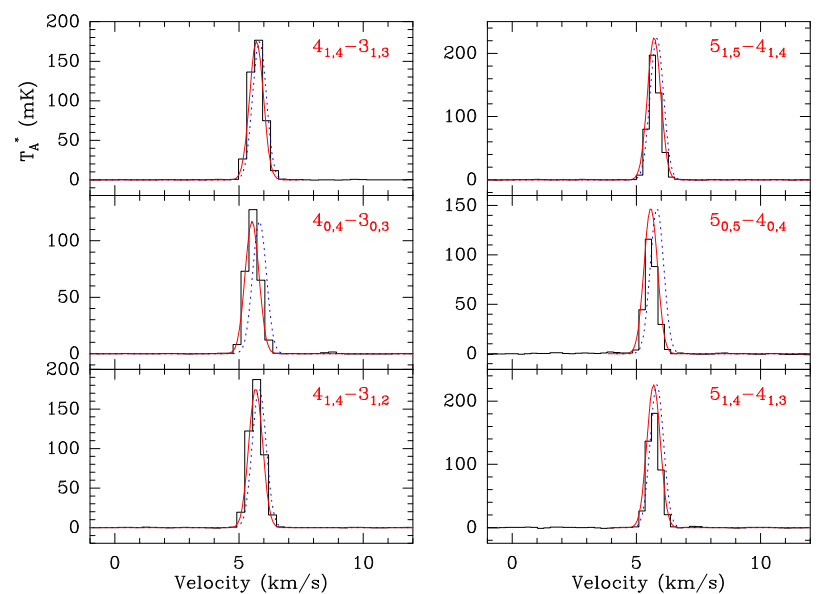

Fig. 3. Observed lines of $l-\mathrm{H}_{2} \mathrm{C}_{4}$ in TMC-1 in the $31.0-50.4 \mathrm{GHz}$ range. Curves shown in red and green are the computed synthetic spectra using the observed frequencies and the CDMS predictions, respectively. Frequencies and line parameters are given in Table 2.

about $30 \mathrm{kHz}$ for the para species) between the observed and predicted frequencies from CDMS. We observed a total of six rotational transitions with $J_{\text {up }}=4$ and 5 and $K_{a}=0$ and 1 . Four of them pertain to ortho- $l-\mathrm{H}_{2} \mathrm{C}_{4}$ and two pertain to para$l-\mathrm{H}_{2} \mathrm{C}_{4}$. All the line parameters are given in Table 2 . From the observed integrated line intensities, we obtained a $T_{r}=10 \mathrm{~K}$ and column densities for the ortho and para species of $\mathrm{N}$ (ortho$\left.l-\mathrm{H}_{2} \mathrm{C}_{4}\right)=(2.5 \pm 0.8) \times 10^{12} \mathrm{~cm}^{-1}$ and $\mathrm{N}\left(\right.$ para- $\left.l-\mathrm{H}_{2} \mathrm{C}_{4}\right)=(8.0 \pm$ $2.3) \times 10^{11} \mathrm{~cm}^{-1}$. The ortho/para ratio for $l-\mathrm{H}_{2} \mathrm{C}_{4}$ is $3.1 \pm 0.9$.

To date, $l-\mathrm{H}_{2} \mathrm{C}_{6}$ is the larger cumulene carbene observed in space. Its dipole moment is calculated (Maluendes \& McLean 1992) to be larger than those for the smaller cumulenes, with a value of $6.2 \mathrm{D}$. The rotational spectrum was investigated by McCarthy et al. (1997) and the derived spectroscopic parameters are used to predict its transition frequencies. Due to its larger molecular size, many rotational transition for $l-\mathrm{H}_{2} \mathrm{C}_{6}$ can be observed in the $31.0-50.4 \mathrm{GHz}$ frequency range. As for all the other cumulene carbenes, and due to its symmetry, it is necessary to discern between ortho- and para- $l-\mathrm{H}_{2} \mathrm{C}_{6}$. Hence, we observed a total of twenty-one transitions for $l-\mathrm{H}_{2} \mathrm{C}_{6}$, fourteen for ortho- and seven for para- $l-\mathrm{H}_{2} \mathrm{C}_{6}$ (see Fig. 4). Line parameters are collected in Table 2 . From the observed inte-
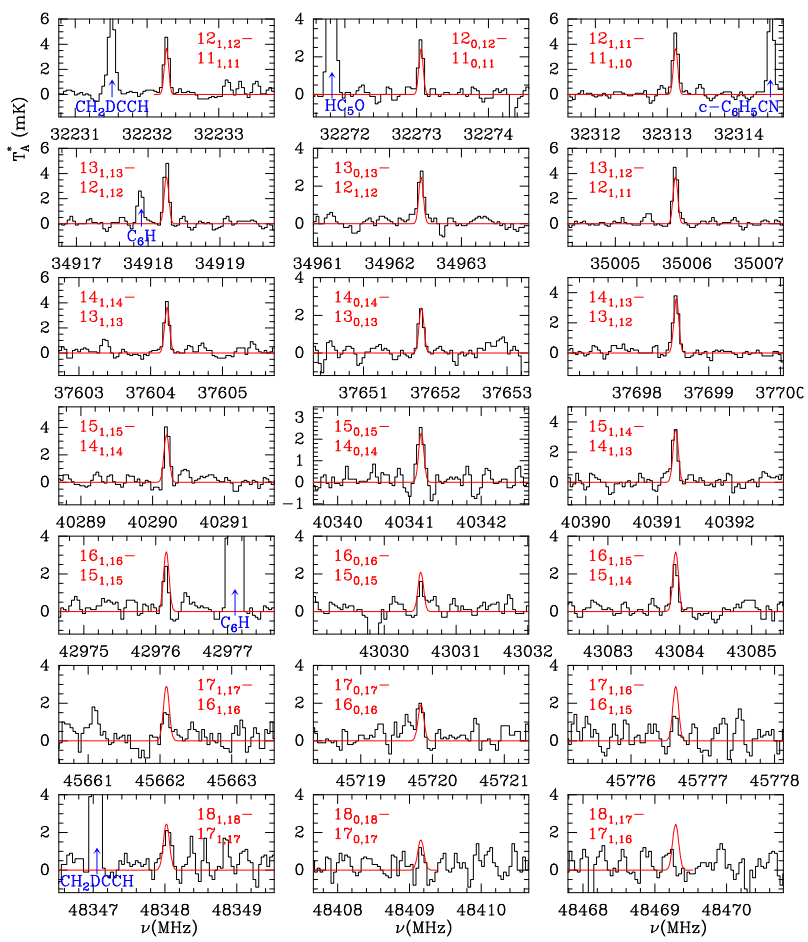

Fig. 4. Observed lines of $l-\mathrm{H}_{2} \mathrm{C}_{6}$ in TMC-1 in the $31.0-50.4 \mathrm{GHz}$ range. Curves shown in red are the computed synthetic spectra. Frequencies and line parameters are given in Table 2 .

grated line intensities, we derived a $T_{r}=10 \mathrm{~K}$ and the column densities $\mathrm{N}$ (ortho- $\left.l-\mathrm{H}_{2} \mathrm{C}_{6}\right)=(6.0 \pm 1.8) \times 10^{10} \mathrm{~cm}^{-1}$ and $\mathrm{N}$ (para$\left.l-\mathrm{H}_{2} \mathrm{C}_{3}\right)=(2.0 \pm 0.6) \times 10^{10} \mathrm{~cm}^{-1}$. The ortho/para ratio was calculated to be $3.0 \pm 0.9$.

From our observations, we obtain the following relative abundances for $l-\mathrm{H}_{2} \mathrm{C}_{3} / l-\mathrm{H}_{2} \mathrm{C}_{4} / l-\mathrm{H}_{2} \mathrm{C}_{5} / l-\mathrm{H}_{2} \mathrm{C}_{6}$ in TMC- 1 , $344 / 561 / 1 / 4.4$. $l-\mathrm{H}_{2} \mathrm{C}_{4}$ is the most abundant cumulene carbene in TMC-1, followed by $l-\mathrm{H}_{2} \mathrm{C}_{3}$. The larger species, $l-\mathrm{H}_{2} \mathrm{C}_{5}$ and $l-\mathrm{H}_{2} \mathrm{C}_{6}$, are much less abundant compared to the shorter cumulene chain, with $l-\mathrm{H}_{2} \mathrm{C}_{6}$ being 4.4 times more abundant than the odd member $l-\mathrm{H}_{2} \mathrm{C}_{5}$. It is worth noting that, within the uncertainties, the four cumelenes studied in this work have an ortho/para abundance ratio of 3 . Hence, no significant ortho to para conversion can be noticed for these molecules.

\subsection{Chemistry of cumulene carbenes}

In order to understand how cumulene carbenes $l-\mathrm{H}_{2} \mathrm{C}_{n}$ can be formed in TMC-1, we carried out gas-phase chemical modelling calculations. We adopted typical conditions of cold dark clouds, that is, a volume density of $\mathrm{H}$ nuclei of $2 \times 10^{4} \mathrm{~cm}^{-3}$, a gas kinetic temperature of $10 \mathrm{~K}$, a visual extinction of $30 \mathrm{mag}$, a cosmic-ray ionisation rate of $\mathrm{H}_{2}$ of $1.3 \times 10^{-17} \mathrm{~s}^{-1}$, and the so-called set of low-metal elemental abundances (e.g., Agúndez \& Wakelam 2013). We used the chemical network RATE12 from the UMIST database (McElroy et al. 2013), updated with results from Lin et al. (2013) and with the subset of gas-phase chemical reactions revised by Loison et al. (2017) in their study of the chemistry of $\mathrm{C}_{3} \mathrm{H}$ and $\mathrm{C}_{3} \mathrm{H}_{2}$ isomers.

Among the family of carbenes $l-\mathrm{H}_{2} \mathrm{C}_{n}$, the one for which the chemistry is better constrained is by far the smallest member $l$ $\mathrm{H}_{2} \mathrm{C}_{3}$, which has been discussed in detail by Loison et al. (2017). This species is mainly formed upon dissociative recombination with electrons of the linear and cyclic isomers of $\mathrm{C}_{3} \mathrm{H}_{3}^{+}$, which 


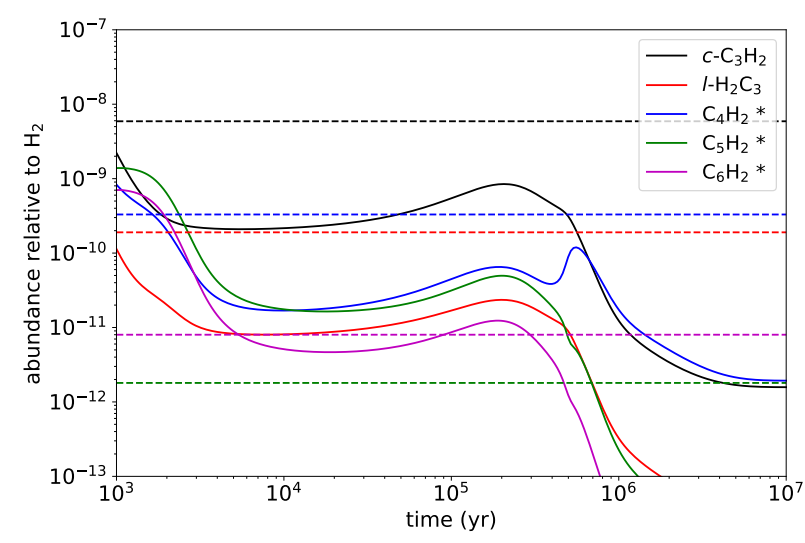

Fig. 5. Calculated fractional abundances of various hydrocarbons as a function of time. The asterisk in the legend means that the chemical model does not distinguish between different isomers. The abundances observed in TMC-1 for $c-\mathrm{C}_{3} \mathrm{H}_{2}$ (Cernicharo et al. 2021a) and $l-\mathrm{H}_{2} \mathrm{C}_{n}$ with $n=3-6$ (this work) are indicated by dashed horizontal lines.

in turn are formed through the radiative association of $\mathrm{C}_{3} \mathrm{H}^{+}$and $\mathrm{H}_{2}$. If we focus on the so-called early time, a few $10^{5} \mathrm{yr}$, where gas-phase chemical models of cold dark clouds reproduce better TMC-1 observations (e.g., Agúndez \& Wakelam 2013), the calculated abundance is about one order of magnitude below the observed value (see Fig. 5), but the calculated cyclic-to-linear abundance ratio agrees very well with the observed value of 31 (Cernicharo et al. 2021a; this work). For members of the series $l-\mathrm{H}_{2} \mathrm{C}_{n}$ with $n>3$, information on the chemistry of the different possible isomers is poorly known and thus chemical networks, such as UMIST RATE12, do not distinguish between them. The calculated abundances of $\mathrm{C}_{4} \mathrm{H}_{2}$ and $\mathrm{C}_{6} \mathrm{H}_{2}$ agree within a factor of 2 and 3 with the observed abundances of $l-\mathrm{H}_{2} \mathrm{C}_{4}$ and $l-\mathrm{H}_{2} \mathrm{C}_{6}$, respectively (see Fig. 5). Although one must keep in mind that observations only refer to the cumulene, while the model also includes other isomers, in particular the more stable non-polar species $\mathrm{HC}_{n} \mathrm{H}$. If the isomer $\mathrm{HC}_{n} \mathrm{H}$ is significantly more abundant than $\mathrm{H}_{2} \mathrm{C}_{n}$ for $n=4,6$ in TMC-1, then the abundances calculated by the chemical model for $\mathrm{C}_{4} \mathrm{H}_{2}$ and $\mathrm{C}_{6} \mathrm{H}_{2}$ would be too low. In the case of $\mathrm{C}_{5} \mathrm{H}_{2}$, the calculated peak abundance is about 30 times lower than the observed abundance of $l-\mathrm{H}_{2} \mathrm{C}_{5}$ (see Fig. 5), although this may not be a problem if the more stable isomer $\mathrm{HC}_{5} \mathrm{H}$ is substantially more abundant than the carbene $l-\mathrm{H}_{2} \mathrm{C}_{5}$.

For $l-\mathrm{H}_{2} \mathrm{C}_{n}$ with $n>3$, the chemical route analogous to that forming $l-\mathrm{H}_{2} \mathrm{C}_{3}$ has variable degrees of efficiency. For example, formation of $\mathrm{C}_{4} \mathrm{H}_{3}^{+}$is relatively efficient thanks to the radiative association between $\mathrm{C}_{4} \mathrm{H}_{2}^{+}$and $\mathrm{H}$ (McEwan et al. 1999). For $n=5$, the route does not work because $\mathrm{C}_{5} \mathrm{H}^{+}$does not react with $\mathrm{H}_{2}$ (McElvany \& Dunlap 1987; Bohme \& Wlodek 1990), while formation of $\mathrm{C}_{6} \mathrm{H}_{3}^{+}$is uncertain due to the unknown reactivity of $\mathrm{C}_{6} \mathrm{H}_{2}^{+}$with $\mathrm{H}_{2}$ (Anicich 2003). Further studies of reactions involving hydrocarbon ions, in particular regarding isomer differentiation, are highly desirable. According to the chemical model, reactions of $\mathrm{C}_{n} \mathrm{H}^{-}$anions with $\mathrm{H}$ atoms are a major route to $\mathrm{C}_{n} \mathrm{H}_{2}$ molecules, such as $\mathrm{C}_{4} \mathrm{H}_{2}, \mathrm{C}_{5} \mathrm{H}_{2}$, and $\mathrm{C}_{6} \mathrm{H}_{2}$. These reactions have been studied in the laboratory for anions $\mathrm{C}_{n} \mathrm{H}^{-}$with $n=2,4,6$, and 7 and have been found to be rapid and to yield $\mathrm{C}_{n} \mathrm{H}_{2}$ as a main product (Barckholtz et al. 2001). The reaction with $n=5$, although not studied, is likely to behave similarly. It is however unknown whether the carbene isomer $\mathrm{H}_{2} \mathrm{C}_{n}$ or the more stable $\mathrm{HC}_{n} \mathrm{H}$ is preferentially formed. It would be very helpful to investigate this particular point.
Other formation routes, apart from $\mathrm{C}_{n} \mathrm{H}_{m}^{+}+e^{-}$and $\mathrm{C}_{n} \mathrm{H}^{-}+\mathrm{H}$, can be provided by neutral-neutral reactions. For example, the chemical model points to the reaction between atomic $\mathrm{C}$ and the propargyl radical $\left(\mathrm{CH}_{2} \mathrm{CCH}\right)$, which was recently detected in TMC-1 (Agúndez et al. 2021), as a source of $\mathrm{C}_{4} \mathrm{H}_{2}$ isomers. This reaction is assumed to be fast by Loison et al. (2017), but calculations of the rate coefficient and product distribution at low temperatures are needed. Similarly, the reaction $\mathrm{C}+\mathrm{C}_{4} \mathrm{H}_{3}$ is assumed to proceed quickly by Smith et al. (2004) and provides an important route to $\mathrm{C}_{5} \mathrm{H}_{2}$ isomers, but more detailed studies on this reaction are necessary. Finally, we note that the cyclic $\mathrm{C}_{5} \mathrm{H}_{2}$ isomer $c-\mathrm{C}_{3} \mathrm{HCCH}$ recently detected by Cernicharo et al. (2021a) is most likely formed through the reaction between $\mathrm{CCH}$ and $c-\mathrm{C}_{3} \mathrm{H}_{2}$.

Acknowledgements. This research has been funded by ERC through grant ERC-2013-Syg-610256-NANOCOSMOS. Authors also thank Ministerio de Ciencia e Innovación for funding support through projects AYA2016-75066-C2-1-P, PID2019-106235GB-I00 and PID2019-107115GBC21/AEI/10.13039/501100011033. MA thanks Ministerio de Ciencia e Innovación for grant RyC-2014-16277.

\section{References}

Agúndez, M., \& Wakelam, V. 2013, Chem. Rev., 113, 8710

Agúndez, M., Cabezas, C., Tercero, B., et al. 2021, A\&A, 647, L10

Anicich, V. G. 2003, JPL Publication 03-19

Araki, M., Takano, S., Sakai, N., et al. 2017, ApJ, 847, 51

Barckholtz, C., Snow, T. P., \& Bierbaum, V. M. 2001, ApJ, 547, L171

Bohme, D. K., \& Wlodek, S. 1990, Int. J. Mass Spectrom. Ion Proc., 102, 133

Cernicharo, J. 1985, Internal IRAM Report (Granada: IRAM)

Cernicharo, J. 2012, in European Conference on Laboratory Astrophysics, eds.

C. Stehlé, C. Joblin, \& L. d'Hendecourt, EAS Publ. Ser., 58, 251

Cernicharo, J., \& Guélin, M. 1987, A\&A, 176, 299

Cernicharo, J., Gottlieb, C. A., Guélin, M., et al. 1991a, ApJ, 368, L39

Cernicharo, J., Gottlieb, C. A., Guélin, M., et al. 1991b, ApJ, 368, L43

Cernicharo, J., Heras, A. M., Tielens, A. G. G. M., et al. 2001, ApJ, 546, L123

Cernicharo, J., Guélin, M., Agúndez, M., et al. 2018, A\&A, 618, A4

Cernicharo, J., Marcelino, N., Agúndez, M., et al. 2020, A\&A, 642, L8

Cernicharo, J., Agúndez, M., Cabezas, C., et al. 2021a, A\&A, 649, L5

Cernicharo, J., Cabezas, C., Endo, Y., et al. 2021b, A\&A, 646, L3

Cernicharo, J., Cabezas, C., Bailleux, S., et al. 2021c, A\&A, 646, L7

Defrees, D. J., \& McLean, A. D. 1986, ApJ, 308, 31

Fossé, D., Cernicharo, J., Gerin, M., \& Cox, P. 2001, ApJ, 552, 168

Gottlieb, C. A., McCarthy, M. C., Gordon, V. D., et al. 1998, ApJ, 509, L141

Guélin, M., Müller, S., \& Cernicharo, J. 2000, A\&A, 363, L9

Herbst, E. 1978, ApJ, 222, 508

Kawaguchi, K., Kaifu, N., Ohishi, M., et al. 1991, PASJ, 43, 607

Khalifa, M. B., Sahnoun, E., Wiesenfeld, L., et al. 2019, Phys. Chem. Chem. Phys., 21, 1443

Killian, T. C., Vrtilek, J. M., Gottlieb, C. A., et al. 1990, ApJ, 365, L89

Langer, W. D., Velusamy, T., Kuiper, T. B. H., et al. 1997, ApJ, 480, L63

Lin, Z., Talbi, D., Roueff, E., et al. 2013, ApJ, 765, 80

Loison, J.-C., Agúndez, M., Wakelam, V., et al. 2017, MNRAS, 470, 4075

Maluendes, S. A., \& McLean, A. D. 1992, Chem. Phys. Lett., 200, 511

McCarthy, M. C., Travers, M. J., Kovács, A., et al. 1997, Science, 275, 518

McElroy, D., Walsh, C., Markwick, A. J., et al. 2013, A\&A, 550, A36

McElvany, S. W., Dunlap, B. I., \& OḰeefe, A., 1987, J. Chem. Phys., 86, 715

McEwan, M. J., Scott, G. B. I., Adams, N. G., et al. 1999, ApJ, 513, 287

Müller, H. S. P., Schlöder, F., Stutzki, J., \& Winnewisser, G. 2005, J. Mol. Struct., 742, 215

Oswald, M., \& Botschwina, P. 1995, J. Mol. Spectrosc., 169, 181

Pardo, J. R., Cernicharo, J., \& Serabyn, E. 2001, IEEE Trans. Antennas Propag., 49, 12

Sattelmeyer, K. W., \& Stanton, J. F. 2000, J. Am. Chem. Soc., 122, 8220

Seburg, R. A., McMahon, R. J., Stanton, J. F., \& Gauss, J. 1997, J. Am. Chem.

Soc., 119, 10838

Smith, I. W. M., Herbst, E., \& Chang, Q. 2004, MNRAS, 350, 323

Tercero, F., López-Pérez, J. A., Gallego, F., et al. 2021, A\&A, 645, A37

Thaddeus, P., Vrtilek, J. M., \& Gottlieb, C. A. 1985, ApJ, 299, L63

Travers, M. J., Chen, W., Novick, S. E., et al. 1996, J. Mol. Spectrosc., 180, 75

Travers, M. J., McCarthy, M. C., Gottlieb, C. A., \& Thaddeus, P. 1997, ApJ, 483,

L135

Vrtilek, J. M., Gottlieb, C. A., Gottlieb, E. W., et al. 1990, ApJ, 364, L53 